\title{
EVALUATION OF THE QUALITY STANDARDS OF THE WATER DISCHARGED INTO THE SEA AFTER WASHING THE EXHAUST GASES
}

\author{
Cojocaru Remus-Cristinel ${ }^{1}$ \\ ${ }^{1}$ Constanta Maritime University, Doctoral School of Mechanical Engineering and Mechatronic, 104 Mircea cel Batran \\ Street, 900663, Constanta, Romania, email costi.cojo@yahoo.com
}

\begin{abstract}
The main objective of this paper is to propose technical solutions for monitoring and recording data for a gas washing system on board a ship and to maintain in standard parameters the quality of surface water following the discharge of gas washing water from installations from the ship. The specific objectives of achieving the general objective are: the methods for evaluating the laboratory samples from the washing water evacuation, modeling the dynamics of the washing water and modeling the dispersion of the scrubber washing water on board for a case study, evaluation of the quality standards of the water discharged into the sea after washing the gases, the elements of calculation, modeling and graphical representation are present.
\end{abstract}

Key words : discharge, evaluation, exhaust, gas,quality,sea,standard, water.

\section{EVALUATION OF LABORATORY SAMPLES FROM WASHING WATER DISCHARGE}

The continuous monitoring of the required parameters of the exhaust gas cleaning system (EGCS) is used, depending on:

- IMO requirements (MEPC.259 (68) 2015 Guidelines for exhaust gas cleaning systems) EU Sulfur Directive (EU / 2012/33;

- All ships are equipped with continuous monitoring equipment to automatically record the required parameters;

- The IMO encourages regular monitoring to test additional parameters with on-site sampling, using measurement techniques that are more advanced than possible during continuous monitoring;

- In 2016, a total of 79 samples were collected and analyzed from the first 23 ships with EGCS.

Sampling continued and in 2018 a re-analysis was performed on a total of 281 samples taken from 53 vessels.

\section{SAMPLING AND METHODS OF} ANALYSIS

\subsection{Sampling of probes:}

Samples shall be collected and analyzed in accordance with a standard protocol developed in cooperation with laboratories. The samples are taken by the environmental officers and the ship's engineers, following a training program on board. The basic data for the test include values for EGCS tower input / output.

The extended sample database also includes samples from several vessels with filtration with wash water installed, providing a fourth sample from a point before this filter.

\subsection{The analysis:}

The analysis of the samples is performed by ISO 17025 certified laboratories using approved methods (or equivalent) to test 54 parameters, including PAHs and metals.

A "net post-EGCS" methodology is used to compare with different water quality standards, with the additional analytical step of using a low average, excluding statistical aberrant values more than three standard deviations from the average.

\section{COMPARISON WITH WATER QUALITY STANDARDS \\ - $\quad$ Sample analysis shows average levels of PAH and nitrates below IMO washing water criteria \\ - Average crude PAH and nitrate concentrations as\% of IMO criteria}


- Flush water discharge limitations vary depending on the EGCS wash water flow rate, ie the higher the wash water flow rate, the lower the allowable concentration.

- Here the weighted average post-EGCS gross concentrations are compared with the lowest theoretical requirements.

- Both post-EGCS PAH values for phenanthrene and the mean sum of all detected PAH values are below the strictest IMO requirements.

This comparison is for illustrative purposes only and does not constitute the approval of any ship with IMO requirements (Table 1)[1].

Table 1. IMO requirements for PAH and nitrate

\begin{tabular}{|c|c|c|}
\hline Compund & $\begin{array}{c}\text { Lowest IMO } \\
\text { criteria (based } \\
\text { on a flow rate } \\
\text { of } 90 \mathrm{t} / \mathrm{MWh})\end{array}$ & $\begin{array}{c}\text { Average gross } \\
\text { concentration } \\
\text { after EGCS }\end{array}$ \\
\hline $\mathrm{PAH}$ & $25 \mu \mathrm{g} / \mathrm{L}$ & $1.77 \mu \mathrm{g} / \mathrm{L}$ \\
\hline Nitrate & $30 \mathrm{mg} / \mathrm{L}$ & $0.8 \mathrm{mg} / \mathrm{L}$ \\
\hline
\end{tabular}

\section{WASHING WATER EVALUATION}

Comparison of wash water with different water standards is not intended to indicate compliance with them - only to illustrate the quality in an easy to understand way. The comparison is made considering the criteria of several standards:

- German Waste Water Ordinance: Limitations on point sources of wastewater from bio-waste treatment

- EU surface water standards part of the EU Water Framework Directive; a water quality standard showing the maximum permissible concentration in inland surface waters.

- This method uses the difference between the mean of the input values and the mean of the post-EGCS values (sampling point 2 - point 1 ).

- All undetected sampling parameters receive a value equal to $50 \%$ of the detection limit of laboratory equipment.

The results presented exclude statistical values greater than three standard deviations $(3 \sigma)$ from the mean value of the sample parameter (Figure 1) [1],[2], [3], [4], [5], [6].

- Comparing the wash water with different water standards is not intended to indicate compliance with them - just to illustrate the quality in an easy way to underestand .
- The study and comparison with water quality standards does not constitute an environmental impact assessment.

- The aim of this study was to present a snapshot of average wash water concentrations. It was not within the scope of this assessment to identify the relationships or correlations between the concentration of parameters in the wash water and the following factors:

- type and quality of fuel

- fuel consumption

- dilution rates

- seawater inlet flows, EGCS tower and overboard discharge

- sampling motor loads.

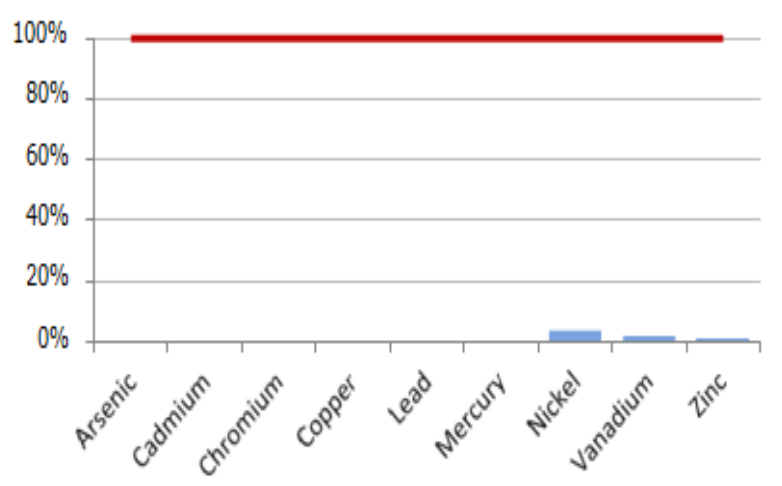

EU Surface Water Standards

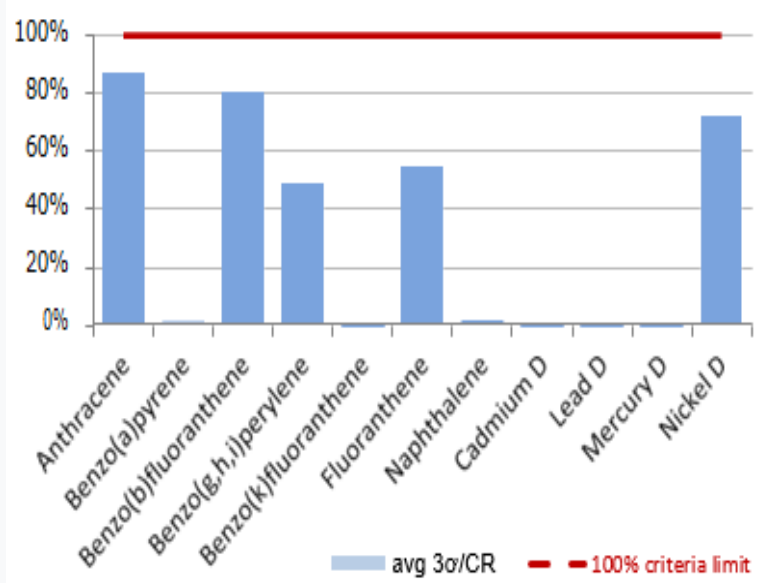

Figure 1 German Wastewater Ordinance and EU standards [1]

The results of the laboratory tests were taken at the nominal value, presumed to be in accordance with the relevant laboratory standards.

Samples are collected and analyzed accordingly (Clean Water Act). Sample kits are prepared and 
provided, each kit containing pre-labeled sample bottles, a sample collection checklist.

\section{CRITERIA FOR EGCS WASH WATER}

Samples were collected by shipboard personnel using a standard training and instruction protocol and analyzed for 54 test parameters at accredited environmental independent laboratories, all using standard methods.

Maritime advisory services were not involved in the sampling process or laboratory analysis, but were hired by the company to:

- compiling and reviewing laboratory test data;

- comparison of wash water test parameters with different water quality standards;

- As there are no water quality standards containing criteria for all parameters tested in the sampling campaign, two terrestrial standards for point source discharge were chosen, in addition to the BMI requirements for EGCS wash water to provide a point reference for total metal concentrations;

- A comparison was also made with water quality standards as a means of assessing PAH levels in context. While water quality standards refer to water bodies rather than a discharge, they illustrate the overall quality of the wash water discharge and offer a broader perspective than comparison with IMO requirements, or simply a compilation of the concentration. media can provide alone.

Unweighted averages of the net post-EGCS concentration were calculated for each parameter and compared with the limits of the relevant criteria for these water quality standards.

The $\mathrm{pH}$ of the point of unloading must be the value that will give at least $6,5 \mathrm{pH}$ four meters from the point of unloading, while the ship is stationary. All $\mathrm{pH}$ values sampled at discharge are above the calculated minimum $\mathrm{pH}$.

The turbidity shall not exceed 25 FNU (formazine neflometric units) or 25 NTU (turflite neflometric units) or equivalent units, above the turbidity of the inlet seawater.

Laboratories analyze all samples using approved methods and issue a final report with all calibrations, standardization and quantification limits.Upon receipt in the laboratory, a checklist is created to document the condition of the sample sets, including temperature, rupture, custody seals and confirmation that all samples are accounted for.
The samples are analyzed during the waiting time required by the standard method.

The results provided by the laboratories include the analysis methodology used and the relevant calibration and standardization procedures (Figure 2)[7].

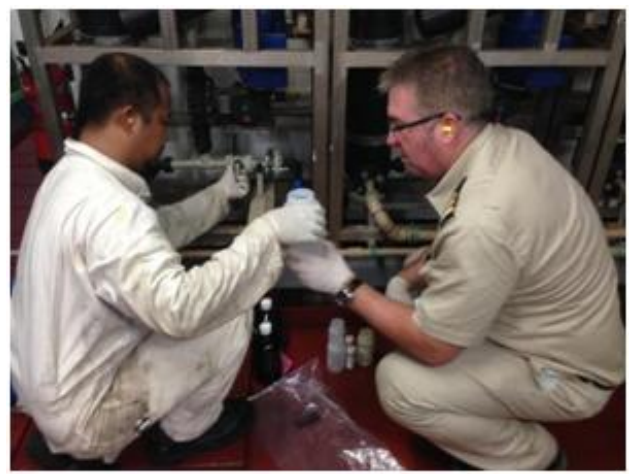

Figure 2 Sampling and analysis [7]

The samples are analyzed during the waiting time required by the standard method (Figure 3 ).

\begin{tabular}{|c|c|c|}
\hline PAHS & Metals* & Other parameters \\
\hline 1. Metilnattalen & Aluminu (Al) & C10-C4OHydrocarbons \\
\hline 2- Metilhatala|en & Cadmiu (Cd) & Chloride \\
\hline Acenaphthene & Chrom $(C r)$ & Total Dissolved Solids \\
\hline Acenaphthylene & Cupru (Cu) & Total Sussended Solds \\
\hline Benzoantracen & Otel $(\mathrm{Fe})$ & AmmoniaasN \\
\hline Benzopiren & Plumb (Pb) & Total Phosphate as PO4 \\
\hline Benzofluoranten & Nickel (Ni) & Total Phosphorus as P \\
\hline Benzoperylene & Thallium (TI) & Total Organic Carbon \\
\hline Benzofluoranten & Vanadiu (V) & Total Kjeldahl Nitrogen \\
\hline Crizena & $\operatorname{Zinc}(2 n)$ & Chromium(VI) \\
\hline Dibenzantracen & Arsenic (As) & pH \\
\hline Fluoranthene & Seleniu (Se) & Nitrate + Nitrate as N \\
\hline $\begin{array}{l}\text { Fluorene } \\
\text { Indemoniren }\end{array}$ & Mercur $(\mathrm{Hg})$ & $\begin{array}{l}\text { Biologcal oxygen demand (BOD) } \\
\text { Chemical oxycen demand (COD) }\end{array}$ \\
\hline $\begin{array}{l}\text { Inderopopren } \\
\text { Nattalină }\end{array}$ & & Organic Nitrogen \\
\hline Phenanthrenene & & Total Nitrogen \\
\hline Piren & & $\begin{array}{c}\text { Ammonium } \\
\text { Diesel RangeOrganics (DRO) }\end{array}$ \\
\hline
\end{tabular}

Figure 3 Parameters analyzed

A significant number of samples for each parameter are "undetected" below the limits of laboratory detection. In environmental testing, it is technically impossible to verify the complete absence of an analyte (Figure 4) [2].

If the analyte is not present or present at a concentration below the detection limit, the laboratory will report a non-detect (ND). 
- An analyte is reliably reported as present only when the test result exceeds the detection limit. For the results reported as ND, it was assumed that the analyte concentration in the sample was half the detection limit (DL).

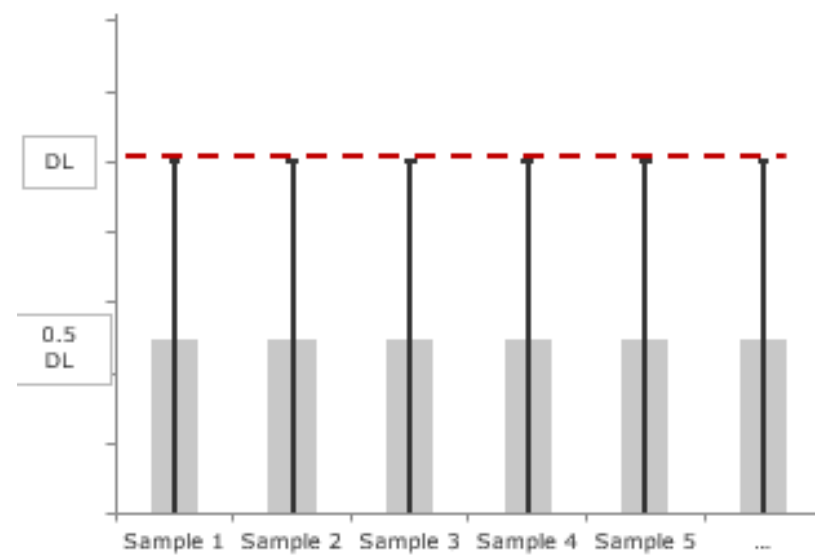

Figure 4 Samples with undetectable ND

DL is provided for each analyte and sample. This means that the analyte concentration is most likely swollen when calculating the average concentration because an ND can actually be zero, while from a chemical analytical point of view, it cannot be definitively identified as zero.

- Certain parameters are almost always below the detection limit at the post-tower output sample.

- An ND is considered to be half of the DL, so the result has more uncertainty, although the margin of error is below the DL.

- For a given parameter, the lower the detection rate, the more likely the average concentration is below DL, but the higher the margin of error.

\section{RESULTS}

Upon receipt in the laboratory, a checklist is created to document the condition of the sample sets, including temperature, rupture, custody seals and confirmation that all samples are accounted for.

\section{concentrations \\ - Calculation of "net post-EGCS"}

- If the seawater in the environment already has a high concentration of the parameter in question, the concentration after the EGCS tower (and in the discharge overboard) may be increased, but not necessarily due to the EGCS process.

- To understand how the EGCS process affects water quality *, a distinction is made between the post-EGCS crude concentration and the postEGCS net concentration (Figure 5).
Post - EGCS concentration $=$ pre-EGCS concentration

(2) - Received seawater concentration (1)
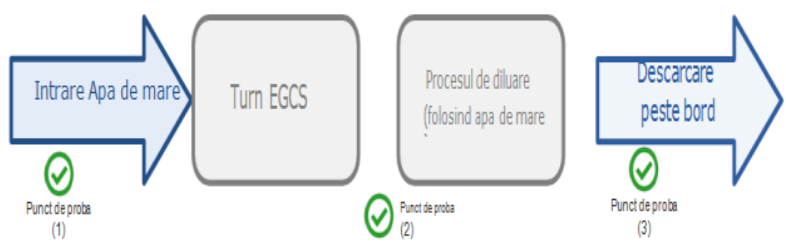

Figure 5 EGCS concentrations

In some cases, the net concentration is negative. This negative result is taken at face value, which is assumed to be valid because there is a seawater filter between the seawater inlet and the EGCS tower.

The intention of using the net concentration is to correct the amount already present in the inlet seawater, giving a clearer idea of how EGCS contributes to the change of the parameter concentration.

The results obtained show:

- Distribution "detects", "does not detect" and statistical values for input and post-EGCS samples (Figure 6).

- Distributions of intake and post-EGCS samples for anthracene and nickel (Figure 7).

\section{- Positive preliminary results for washing water filtration}

Although not further discussed in this evaluation, the results for 11 samples with discharge filtering were also reviewed. Initial tests and laboratory analysis of the filtered material and post-filtration wash water indicate an effective reduction potential for the parameters (Table 2) [3], [4].

Table 2. Washing water filtration results

\begin{tabular}{|c|c|l|l|}
\hline Parameter & $\begin{array}{c}\text { Effective } \\
\text { filtering }\end{array}$ & Parameter & $\begin{array}{c}\text { Effective } \\
\text { filtering }\end{array}$ \\
\hline Arsenic & $\mathrm{P}$ & Antracen & $\mathrm{P}$ \\
\hline Cadmium & $\mathrm{P}$ & $\begin{array}{l}\text { Benzo (a) } \\
\text { antracen }\end{array}$ & $\mathrm{P}$ \\
\hline Chrom & $\mathrm{P}$ & $\begin{array}{l}\text { Benzo (b) } \\
\text { fluoranten }\end{array}$ & $\mathrm{P}$ \\
\hline Copper & $\mathrm{P}$ & $\begin{array}{l}\text { Benzo (g,h,i) } \\
\text { perilena }\end{array}$ & $\mathrm{P}$ \\
\hline
\end{tabular}




\begin{tabular}{|c|l|l|l|}
\hline Steel & $\mathrm{P}$ & Crizena & $\mathrm{P}$ \\
\hline Lead & $\mathrm{P}$ & $\begin{array}{l}\text { Fluoranthen } \\
\mathrm{e}\end{array}$ & $\mathrm{P}$ \\
\hline Mercury & $\mathrm{P}$ & Fluorene & $\mathrm{P}$ \\
\hline Nickel & $\mathrm{P}$ & Naftalină & $\mathrm{P}$ \\
\hline Vanadium & $\mathrm{P}$ & $\begin{array}{l}\text { Phenanthre } \\
\text { ne }\end{array}$ & $\mathrm{P}$ \\
\hline Zinc & $\mathrm{P}$ & $\begin{array}{l}\text { Pyrene } \\
\mathrm{y}\end{array}$ & $\mathrm{P}$ \\
\hline
\end{tabular}

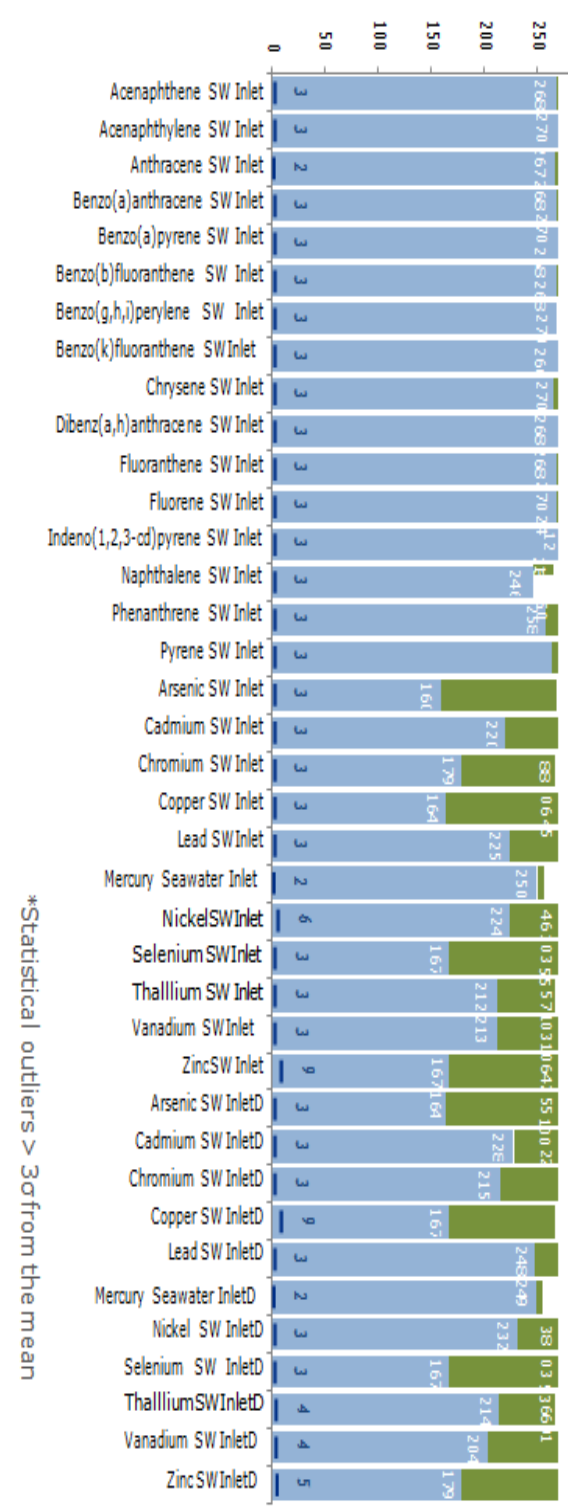

Figure 6 Statistical values for input and post-EGCS tests

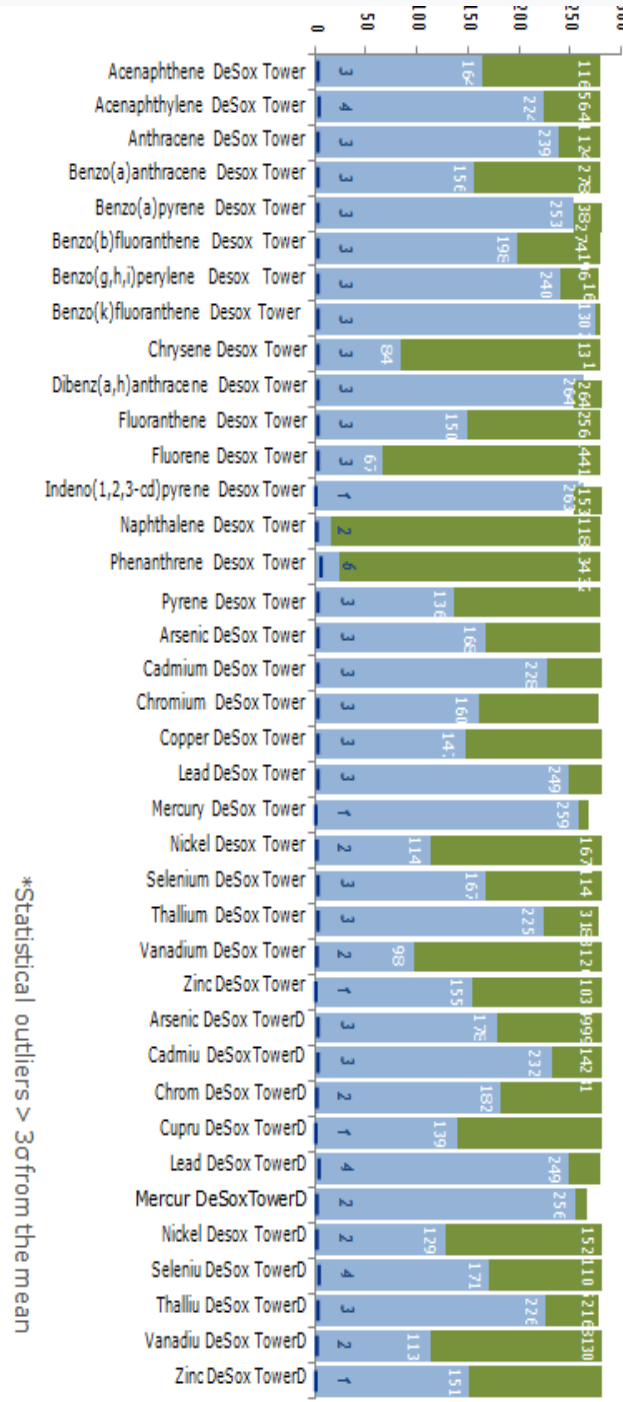

Figure 7 Distributions of intake and post-EGCS samples for anthracene and nickel

IMO encourages regular monitoring to test additional parameters with on-site sampling, using measurement techniques that are more advanced than possible during continuous monitoring [6], [7]. 


\section{CONCLUSIONS}

The following aspects are observed:

- The net post-EGCS average for a number of metallic parameters is extremely low, with post-EGCS output values up to input values: Arsenic, Cadmium, Lead, Mercury, Selenium, Thallium.

- A number of PAH parameters also give a low net result: Benzo (a) pyrene, Benzo (g, h, i) perylene, Benzo (k) fluoranthene.

\section{REFERENCES}

[1] https://www.aquadp.ro/incineratoare/spalare-gaze.

[2]https://www.incineratoare.ro/incineratoare/spalareagazelor

[3] https://inciner.ro/optionale/spalarea-gazelor-emise.

[4]

https://www.aerzen.com/fileadmin/user_upload/02_docu ments/02-02_applications/02-02-

08_marine_industry/A1-050-02__RO.pdf

[5]https://www.alfalaval.ro/industrii/industriaenergetic/motoare-cu-combustie/reducereaemisiilor/reducerea-emisiilor-de-gaz-de-esapament/ [6] Istrate M., 2004, Tehnologii si instalatii pentru reducerea emisiilor poluante, SETIS Publish House, Iasi, Romania.

[7] https://www.youtube.com/watch?v=BIRDUskEnYs 